\title{
DeVelopMent of Micro-Plasma Wire DEPOSITION PROCESS FOR LAYERED MANUFACTURING
}

\author{
JHAVAR, S. \& JAIN, N.K.
}

Abstract: This chapter presents the use of micro-plasma wire depsotion process as an alternative to the existing layer manufacturing procesess for small sized deposition. Experiments at two stages were conducted to identify important process parameters generating regular and smooth track geometry in single and multi-layer deposition. Further investigations were conducted for enhancing the deposition quality of the process by approximating and validating the deposition. The process was found to be capable of fabricating straight walls having total wall width of 2.45 $\mathrm{mm}$ and effective wall width of $2.11 \mathrm{~mm}$. The deposition efficiency was found to be $87 \%$ for the maximum deposition rate of $42 \mathrm{~g} / \mathrm{h}$. The microscopic examination and micro-hardness measurements revealed that the deposited wall is free from cracks, porosity and inclusions. This study confirms the capability of micro-plasma wire depsotion process as an alternative to various established layer manufacturing processes used for meso-scale fabrication.

Key words: layer manufacturing, plasma deposition, characterization, deposition rate, tool steel
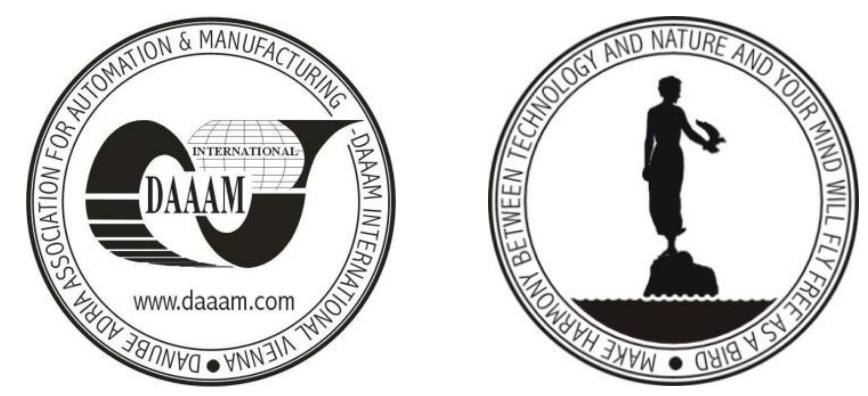

Authors' data: Jhavar, S[uyog]; Jain, N[eelesh] K[umar], Discipline of Mechanical Engineering, Indian Institute of Technology Indore, 453446, MP, India, maheshwarisuyog@gmail.com,nkjain@iiti.ac.in

This Publication has to be referred as: Jhavar, S[uyog] \& Jain, N[eelesh] (2014). Development of Micro-Plasma Wire Deposition Process for Layered Manufacturing, Chapter 20 in DAAAM International Scientific Book 2014, pp.239-256, B. Katalinic (Ed.), Published by DAAAM International, ISBN 978-3-901509-98-8, ISSN 17269687, Vienna, Austria

DOI: $10.2507 /$ daaam.scibook.2014.20 
Jhavar, S. \& Jain, N.: Development of Micro-Plasma Wire Deposition Process for L...

\section{Introduction}

Layer manufacturing (LM) is an advance forming process in which material is deposited layer by layer and then two consecutive deposited layers are joined together either to (i) produce new net-shaped or near net-shaped components; or (ii) to add delicate features to the existing components. Fig. 1 shows the elements of a typical LM system. Each deposited layer is created by rapid solidification of the deposition material over a stationary or moving substrate. The Process eliminates many steps required in the conventional manufacturing such as preparation of drawings at different manufacturing stages, procurement of raw material of specific shape and size, planning of man power, machines and manufacturing processes, intermittent quality checks and allied human errors. LM technology is interdisciplinary in nature utilizing the knowledge of computer aided design/manufacturing (CAD/CAM), robotics, joining, sensing, monitoring, control, etc.

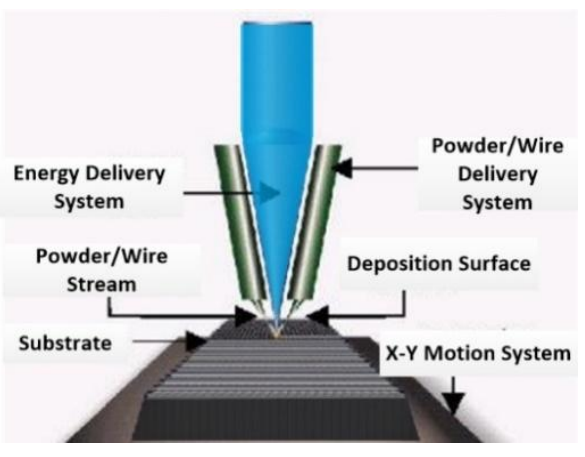

Fig. 1. Elements of a typical layered manufacturing system

Diversified industries are now using LM for various rapid prototyping (RP), rapid manufacturing (RM) and rapid tooling (RT) applications. These include avionics and aerospace industries, automotive, biomedical, nuclear, electronics, toolmaking, special-purpose engineering, repair/remanufacturing and lifestyle Campbell et al (2007). LM processes are used to make components for digital cameras, mobile phones and machine parts as well as interior elements for automobiles, components and modules for aircraft, medical and dental implants and many more. Since 1990 onwards, many LM processes have been developed, patented and commercialized mostly for the non-metallic parts used in the various applications. However, development of LM process for the metallic parts is still challenging and needs lot of research to mature it.

\section{Classification of $\mathrm{LM}$ processes}

Levy et al (2003) reviewed various LM processes (both patented as well as commercialized) used for deposition of metallic materials in various RM and RT applications. Jhavar et al (2013) presented a brief review of various LM processes as 
repairing options for dies and moulds. Laser rapid manufacturing (LRM), laser engineered net shaping (LENS), direct metal deposition (DMD), electron beam melting (EBM), solid freeform fabrication (SFF), three-dimensional welding (3DW) are some of the frequently published variants under LM technology. Various LM processes can be classified either according to the (i) type of heat source used for melting the material: high-energy beam processes using laser or electron beam and electric-arc based processes; (ii) type of deposition material being used: liquid or solid-based. Laser, electron beam and electric arc are the major energy sources used for the LM processes for the metallic materials. Laser and electron beam are more precise energy sources than the electric arc therefore they are more preferred for miniature sized deposition. But, a major drawback is their poor energy conversion efficiency which causes higher energy consumption for fabrication of components, tooling and related applications. Use of energy efficient sources and increase in the deposition rates are the two major concerns for LM processes. Fig. 2 presents classification of LM processes according to the type of energy source used.

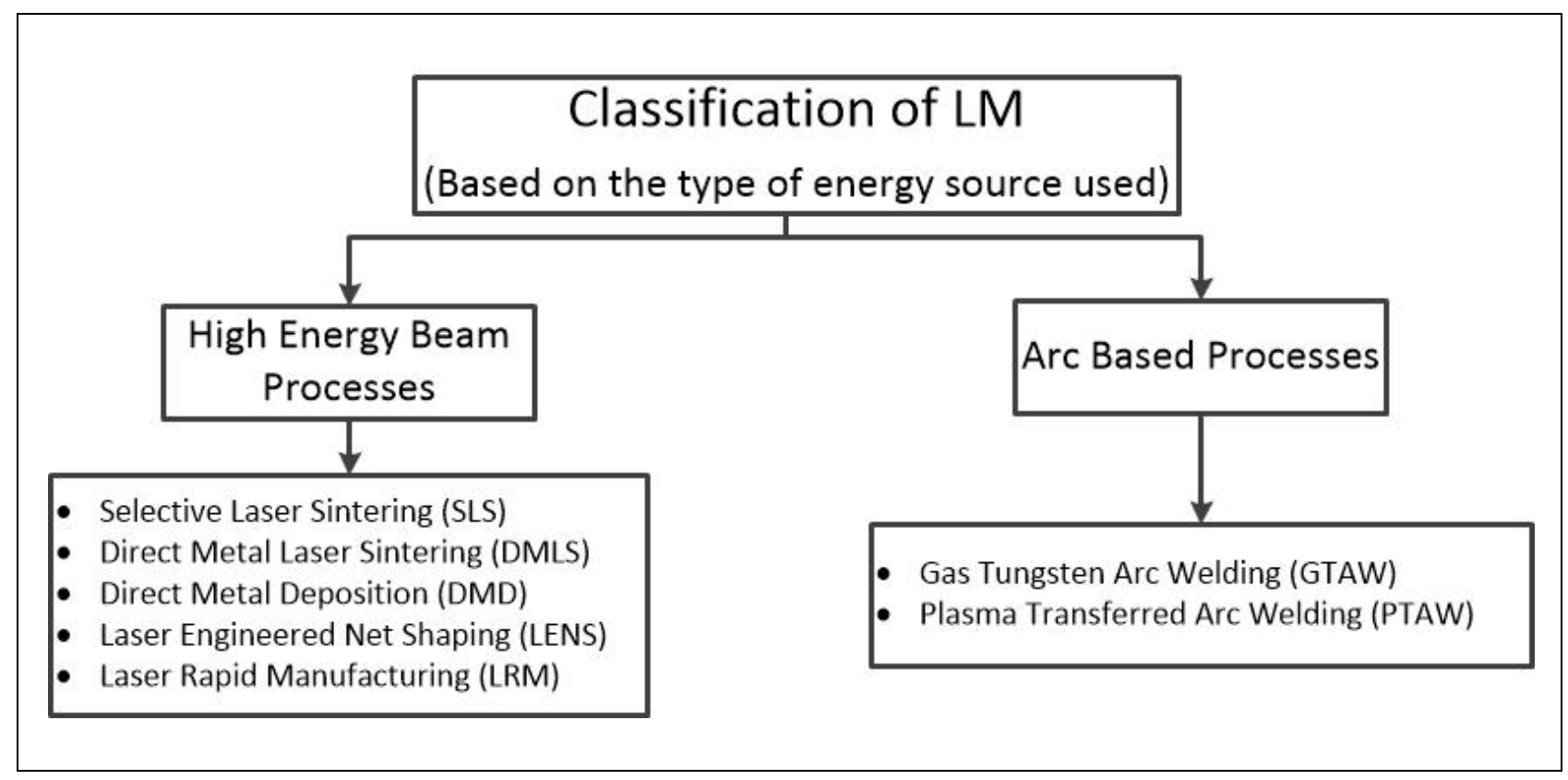

Fig. 2. Classification of the LM processes according to type of energy source

The deposition material can be supplied in the form of either liquid or solid (i.e. powder, wire, pallets, foil, etc.) or both. Fig. 3 presents the classification of the LM processes according to type of the deposition material. Liquid-based LM systems were used during the initial development phase of the RP processes. These systems utilize low melting point deposition material such as wax, polyethylene, silicon rubber, epoxy, ABS etc. for making the prototypes. With the technological advancement, innovative methods of using LM for manufacturing the metallic components and tooling were developed which led to increased use of solid deposition materials in the form of powder and/or wire. Recently developed technological equipment have capabilities to analyse and explore various aspects of using the deposition material in the form of powder/wire of metals, alloys, ceramics and functionally graded materials for the LM processes. 


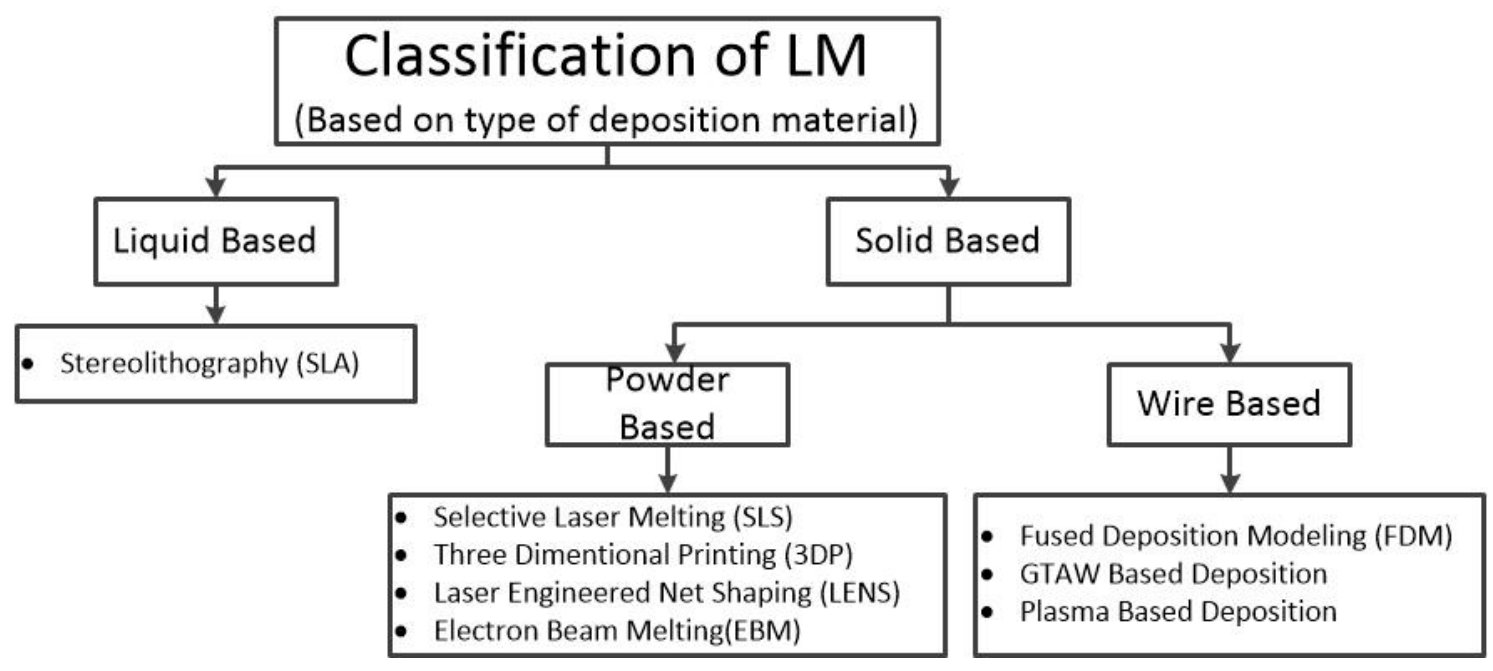

Fig. 3. Classification of LM processes according to type of the deposition material

In the last 20 years, various LM processes have been introduced, developed and patented. Levy et al. (2003), Hopkinson and Dickens (2006), Wohler's survey (2006) and Wong and Hernandez (2012) have reviewed evolution of different LM processes. Tab. 1 presents various LM workstations, commercial names and processes used.

\begin{tabular}{|c|c|c|}
\hline Company/Website & Process & Other details \\
\hline Cubital Ltd., Israel & $\begin{array}{l}\text { Solid Ground Curing } \\
\text { (SGC) }\end{array}$ & $\begin{array}{l}\text { Commercialized in 1986, } \\
\text { Use of ultra-violet (UV) lamp for } \\
\text { plastic/metal curing. }\end{array}$ \\
\hline DTM & $\begin{array}{l}\text { Selective Laser Sintering } \\
\text { (SLS) }\end{array}$ & $\begin{array}{l}\text { Commercialized in 1980s } \\
\text { Use of high power laser }\end{array}$ \\
\hline Stratasys & $\begin{array}{l}\text { Fused Deposition } \\
\text { Modeling (FDM) }\end{array}$ & $\begin{array}{l}\text { Commercialized in } 1980 \mathrm{~s} \\
\text { Use of thin filament wire as deposition } \\
\text { material. }\end{array}$ \\
\hline Helisys & $\begin{array}{l}\text { Laminated Object Method } \\
(\mathrm{LOM})\end{array}$ & $\begin{array}{l}\text { Commercialized in 1980s Use of PVC } \\
\text { Sheet Rolls } \\
\text { Accuracy }-0.2 \mathrm{~mm}(\mathrm{x}, \mathrm{y}) ; 0.3 \mathrm{~mm}(\mathrm{z})\end{array}$ \\
\hline Landfor & Laminated $\mathrm{C}$ & Production of multi-colored parts. \\
\hline Sparx & Hot-Plot & $\begin{array}{l}\text { Commercialized in } 1989 \\
\text { Use of thin PVC Sheet Rolls }\end{array}$ \\
\hline Light Scul & $\begin{array}{l}\text { Design-controlled } \\
\text { Automated Fabrication }\end{array}$ & $\begin{array}{l}\text { Use of metallic sheets } \\
\mathrm{CO}_{2} \text { laser was used for shape cutting. }\end{array}$ \\
\hline DuPont/Teijin Seiki & SOMOS/Soliform & $\begin{array}{l}\text { Commercialized in } 1989 \\
\text { Use of argon ion laser }\end{array}$ \\
\hline Sony & $\begin{array}{l}\text { Solid Creation System } \\
\text { (SCS) }\end{array}$ & $\begin{array}{l}\text { Use of argon ion laser } \\
\text { Use of rubber as deposition material }\end{array}$ \\
\hline Mitsubishi & $\begin{array}{l}\text { Solid Object Ultra-violet } \\
\text { Laser Plotting (SOP) }\end{array}$ & $\begin{array}{l}\text { Use of argon ion laser } \\
\text { Use of epoxy resin as deposition material }\end{array}$ \\
\hline $\begin{array}{l}\text { Electro Optical Systems } \\
\text { (EOS) }\end{array}$ & $\begin{array}{l}\text { Direct Metal Laser } \\
\text { Sintering (DMLS) }\end{array}$ & $\begin{array}{l}\text { Use of light alloys to high-grade steels, } \\
\text { tool steels and superalloys as deposition } \\
\text { material }\end{array}$ \\
\hline
\end{tabular}

Tab. 1. Summary of the major commercialized LM processes 


\section{Review of the past work}

The transition of LM application from polymeric to metallic material has been gradual and challenging. With the availability of several patents and commercial workstations for LM of polymer based materials, the technology has matured enough, but however same is not true for metallic materials. Laser and electron beam are more preferred for miniature sized deposition as they are more precise energy sources than the electric arc. But, a major drawback is their poor energy conversion efficiency which causes higher energy consumption for fabricating the components, tooling and related applications. Suryakumar et al. (2011) have mentioned that the deposition rate achieved by laser or electron beam is of the order of $2-10 \mathrm{~g} / \mathrm{min}$. whereas, electric arc based deposition processes can achieve it in the range of $50-130 \mathrm{~g} / \mathrm{min}$. Therefore, arc based deposition techniques are preferred for bulk deposition on the metallic components for various LM purposes. Use of energy efficient sources and increase in the deposition rates for LM processes are two major issues. Jandric et al. (2004) successfully built three dimensional metallic parts using gas tungsten arc welding (GTAW) process for depositing the material. They reported that the manufactured part was free from cracks, porosity and had uniform microstructure throughout. Akula and Karunakaran (2006) have developed a direct metal rapid tool making process integrating metal inert gas (MIG) and metal active gas welding (MAG) for near-net layer deposition and computer numerical controlled (CNC) milling process for net shaping to manufacture the dies and moulds for the metallic parts. Micro-arc based deposition is one of the recent LM techniques having prospective applications in repairs and fabrication at meso-scale. Horii et al. (2009) reported success in making three dimensional structures using micro-sized wire for miniature deposition through a micro-tungsten inert gas ( $\mu$-TIG) welding system. They mentioned that this can be useful for meso-scale net-shaping. Almeida and Williams (2010) developed out-of-chamber LM using gas metal arc welding (GMAW) to deposit a wall of Ti$6 \mathrm{Al}-4 \mathrm{~V}$. They statistically modelled the process to predict the most appropriate processing parameters. Baufeld et al. (2011) deposited multi-layered single bead wall using a combination of laser beam deposition and GTAW with the help of a 6-axis robotic system. Their results confirm that both laser and GTAW processes can be used for LM applications. Martina et al. (2012) used plasma wire deposition to make walls of Ti-6Al-4V. They designed their experiments using D-optimal design method and achieved $1.8 \mathrm{~kg} / \mathrm{h}$ as the highest deposition rate feeding $1.2 \mathrm{~mm}$ diameter wire at $100 \mathrm{~mm} / \mathrm{s}$.

Therefore, it can be understood that there is a wide gap that exists between the process capabilities of arc-based and high-energy based depositions processes. Highenergy beam based processes are too costly for LM applications requiring miniature or small amount of metallic deposition. No work has been reported on the development of micro-version of arc-based processes which is economical, materialefficient and energy-efficient. 
Jhavar, S. \& Jain, N.: Development of Micro-Plasma Wire Deposition Process for L...

\section{Research objectives}

The present research work was undertaken with the following research objectives so as to bridge the identified research gaps:

1) To develop micro-plasma wire deposition process for LM applications for the metallic materials so as to

- Bridge the gap between the process capabilities of arc-based and high-energy based depositions processes.

- An energy-efficient, material-efficient and environment friendly alternative to the existing LM processes.

2) To identify the ranges of process parameters for $\mu$-plasma wire deposition process for regular deposition.

3) To investigate the surface integrity of the deposited material in order to confirm the process capability for LM applications.

4) To evaluate energy input per unit travel speed of worktable, volumetric feed rate of wire per unit travel speed of worktable and material deposition rate for regular deposition.

5) To identify the process parameters with the lowest energy input per unit travel speed of worktable and highest deposition rate for multi-layer deposition of straight walls.

\section{Design and development of the experiment apparatus}

In the present work, a computer controlled micro-plasma power supply along with its torch was used as the power source and deposition system for the development of the experimental apparatus for micro plasma wire deposition process. This system had maximum plasma power capacity of $450 \mathrm{~W}$ with current varying in the range of 0.1-18 A with a step of 0.1 A. A wire feeding system was designed and developed to ensure an uninterrupted supply of the deposition material. The spool of AISI P20 wire was loaded on the wire-feeding system which can feed the wire at rate of 850,1275 and $1700 \mathrm{~mm} / \mathrm{min}$. The nozzle of micro-plasma welding system was suitably modified for feeding the wire to the melt-pool. A conventional milling machine was used as the manipulator system to provide the required movements in the $\mathrm{X}$ and $\mathrm{Y}$ directions. The manipulator system had capacity to provide variable travel speed of $40,50,63,80,100 \mathrm{~mm} / \mathrm{min}$ in the automatic mode with a positional accuracy of $0.005 \mathrm{~mm}$. Fig. 4 depicts the schematic diagram of the developed experimental apparatus for the micro plasma wire deposition process for the metallic materials.

In order to achieve the research objectives, the experiments were planned and conducted in three stages: (i) pilot experiments for single-track deposition varying the selected process parameters in the entire ranges available on the machine; (ii) forty five main experiments with three replicates for single-track deposition using full 


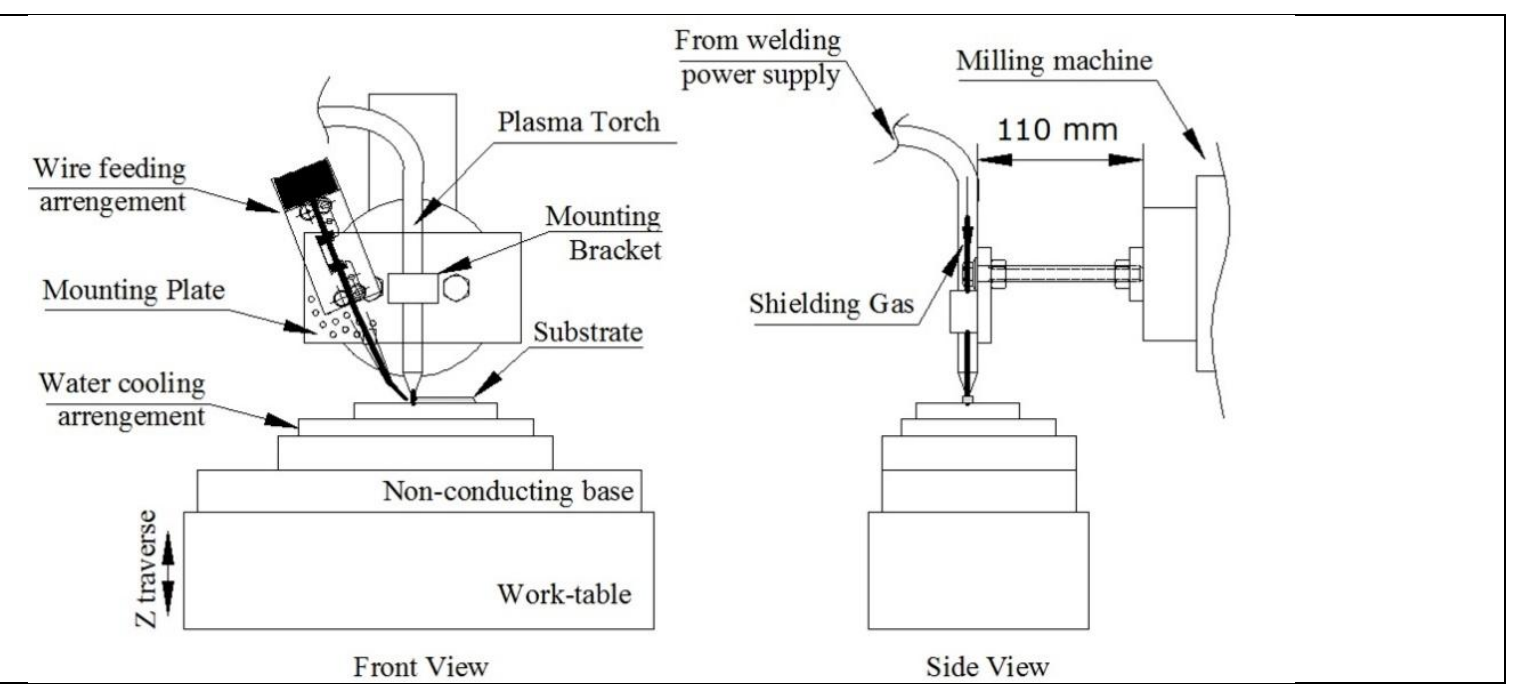

Fig. 4. Schematic diagram of the experimental apparatus developed for the micro plasma wire deposition process

factorial approach; (iii) two experiments for multi-layer deposition with three replicates. Pilot experiments helped to identify the proper ranges/values of the most influencing parameters of micro plasma wire deposition process. Seven parameters were selected to vary during the pilot experiments on the basis of their influence on the performance of the micro plasma wire deposition process. They were plasma power $(P)$, travel speed of the worktable $(v)$, wire feed rate $(f)$, wire feed angle $(\alpha)$, stand-off distance $(X)$, plasma gas flow rate $\left(F_{p}\right)$ and shield gas flow rate $\left(F_{s}\right)$. These parameters were varied in their entire range available on the developed experimental apparatus as mentioned in the Tab. 2. Based upon observations during the pilot experiments, plasma power, travel speed of the worktable and wire feed rate were found to be the most significant parameters affecting the quality of single-track deposition by the micro plasma wire deposition process. The ranges for these three parameters were narrowed down while optimum values of the other four parameters were identified for the main experiments focused on single-track deposition.

\begin{tabular}{|llc|}
\hline Designation: parameter name (unit) & $\begin{array}{c}\text { Range used for the } \\
\text { pilot experiments }\end{array}$ & $\begin{array}{c}\text { Range / value identified for } \\
\text { the main experiments }\end{array}$ \\
\hline P: Plasma power (W) & $50-450$ & $350-450$ \\
\hline $\begin{array}{l}\text { v: } \text { Travel speed of worktable } \\
\text { (mm/min.) }\end{array}$ & $40-160$ & $40-100$ \\
\hline f: Wire feed rate (mm/min.) & $850-1700$ & $850-1700$ \\
\hline$\alpha:$ Wire feed angle (degrees) & $20-60$ & $45 \pm 1^{\circ}$ \\
\hline X: Stand-off distance (mm) & $5-8$ & 5 \\
\hline $\boldsymbol{F}_{\boldsymbol{p}}$ : Plasma gas flow rate $(1 / \mathrm{min})$. & $0.1-0.5$ & 0.4 \\
\hline $\boldsymbol{F}_{\boldsymbol{s}}$ : Shield gas flow rate $(1 / \mathrm{min})$. & $3.0-8.0$ & 5.0 \\
\hline
\end{tabular}

Tab. 2. Input parameters and their ranges used in the pilot experiments 
Jhavar, S. \& Jain, N.: Development of Micro-Plasma Wire Deposition Process for L...

\section{Result and discussion}

It was observed during the pilot experiments that a minimum $300 \mathrm{~W}$ of plasma power was required to melt the stationary AISI P20 wire of $300 \mu \mathrm{m}$. Further, a small portion of power is required to melt the substrate during micro plasma wire deposition process called wetting. This is required to build a strong bond between the consecutive layers. The micro-plasma power source used in the experimental apparatus had capacity to provide maximum power of $450 \mathrm{~W}$. Therefore, plasma power $(P)$ was bracketed between $350-450 \mathrm{~W}$ for the main experiments. Discontinuous tracks were observed when travel speed of the worktable was more than $100 \mathrm{~mm} / \mathrm{min}$, even at the maximum allowable wire feed rate of $1700 \mathrm{~mm} / \mathrm{min}$. Therefore, a range of 40-100 $\mathrm{mm} / \mathrm{min}$ was selected for travel speed of the worktable. Here, the value of travel speed of worktable is limited due to available gearing ratio of the conventional milling machine, which is used as manipulator system in the developed experimental apparatus. All the designed values of wire feed rate were used in the pilot experiments. It was also experimentally found that the wire feed angle of 45 degree could produce good quality deposition at lower plasma power. This is in agreement with the previous work by (Abioye et al., 2013). Stand-off distance (SOD) of $5 \mathrm{~mm}$ was found to be optimum. The lower values of the SOD produces difficulty in smooth wire feeding due to smaller space, while the higher values of SOD resulted in lower plasma power density compelling higher plasma power for deposition, which results in larger HAZ. The similar results were observed by Wang et al. (2003).

Plasma gas flow rate of 0.4 litre per minute $(\mathrm{l} / \mathrm{min}$.) was found to be adequate to transfer plasma power towards the substrate, while shield gas flow rate of $5 \mathrm{l} / \mathrm{min}$ was found to be just sufficient to protect the melt pool from oxidation. It was observed that lower values of the shield gas flow rate allowed the atmospheric gases to react with the melt pool resulting in irregular (i.e., porous and uneven) deposition and spatter during deposition, whereas higher values resulted in wider melt pool generating dimple like impressions over the top surface of the deposition.

Here, the objective of the main experiments was to identify the optimum values of plasma power, wire feed rate and travel speed of the worktable based upon quality of the single-track deposition using AISI P20 wire on the substrate of the same material. Tab. 3 presents the values of the input process parameters and the average values of geometric parameters of single-track depositions in terms of geometrical aspects like deposition width, deposition height, aspect ratio, dilution, and track root angle along with their standard deviation for the 45 main experiments (Jhavar et al 2014a). It also mentions the quality of the deposition in terms of non-uniform (NU) and uniform \& regular (UR). It was observed that the use of higher plasma power and lower wire feed rate caused excess melting of the substrate and deposition material and even evaporation of the deposition material causing discontinuity in the deposition and formation of the cavities which led to either no or very little deposition. While, use of lower plasma power and higher wire feed rate resulted in deposition having lower bonding between the substrate and the deposition material due to insufficient melting of the deposition material. It also resulted in collision of wire with the substrate in the extreme cases resulting in deflection of the deposition material delivery and offsetting the centre of wire from the centre of melt pool. This 
centre offsetting caused irregular depositions due to wrong wire positioning. Hence, wire positioning is critical for better utilization of plasma energy and sound deposition. It was also noted that there is a balance of plasma power and wire feed rate required for the regular and sound deposition.

\begin{tabular}{|c|c|c|c|c|c|c|c|c|c|}
\hline $\begin{array}{l}\text { Trac } \\
\text { k ID }\end{array}$ & $\begin{array}{l}\text { Plasma } \\
\text { Power } \\
\text { (W) }\end{array}$ & $\begin{array}{c}\text { Travel speed } \\
\text { of worktable } \\
(\mathbf{m m} / \mathbf{m i n})\end{array}$ & $\begin{array}{c}\text { Wire Feed } \\
\text { Rate } \\
(\mathrm{mm} / \mathrm{min})\end{array}$ & $\begin{array}{c}\text { Deposition } \\
\text { width }(\mathbf{m m})\end{array}$ & $\begin{array}{c}\text { Deposition } \\
\text { height } \\
(\mathrm{mm})\end{array}$ & $\begin{array}{c}\text { Aspect } \\
\text { Ratio }\end{array}$ & $\begin{array}{c}\text { Dilution } \\
(\%)\end{array}$ & $\begin{array}{c}\text { Track } \\
\text { Root } \\
\text { Angle }\end{array}$ & $\begin{array}{c}\text { Observ } \\
\text { ations }\end{array}$ \\
\hline 1 & 350 & 40 & 1700 & $1.9 \pm 0.1$ & $1.8 \pm 0.08$ & $1.06 \pm 0.069$ & $1.01 \pm 0.04$ & 130 & $\mathrm{NU}$ \\
\hline 2 & 350 & 50 & 1700 & $1.8 \pm 0.08$ & $1.6 \pm 0.06$ & $1.13 \pm 0.058$ & $1.46 \pm 0.05$ & 121 & $\mathrm{NU}$ \\
\hline 3 & 350 & 63 & 1700 & $1.5 \pm 0.06$ & $1.3 \pm 0.05$ & $1.15 \pm 0.055$ & $1.07 \pm 0.03$ & 119 & NU \\
\hline 4 & 350 & 80 & 1700 & $1.4 \pm 0.06$ & $1.2 \pm 0.08$ & $1.17 \pm 0.079$ & $1.72 \pm 0.04$ & 104 & $\mathrm{NU}$ \\
\hline 5 & 350 & 100 & 1700 & $1.2 \pm 0.05$ & $1.0 \pm 0.04$ & $1.20 \pm 0.064$ & $3.49 \pm 0.1$ & 102 & $\mathrm{NU}$ \\
\hline 6 & 350 & 40 & 1275 & $1.6 \pm 0.08$ & $1.4 \pm 0.06$ & $1.14 \pm 0.066$ & $1.02 \pm 0.02$ & 111 & NU \\
\hline 7 & 350 & 50 & 1275 & $1.5 \pm 0.04$ & $1.3 \pm 0.06$ & $1.15 \pm 0.053$ & $1.89 \pm 0.04$ & 111 & $\mathrm{NU}$ \\
\hline 8 & 350 & 63 & 1275 & $1.4 \pm 0.06$ & $1.2 \pm 0.06$ & $1.17 \pm 0.066$ & $2.46 \pm 0.06$ & 103 & $\mathrm{NU}$ \\
\hline 9 & 350 & 80 & 1275 & $1.2 \pm 0.04$ & $1.0 \pm 0.04$ & $1.20 \pm 0.052$ & $2.47 \pm 0.04$ & 106 & $\mathrm{NU}$ \\
\hline 10 & 350 & 100 & 1275 & $1.1 \pm 0.06$ & $0.8 \pm 0.04$ & $1.38 \pm 0.074$ & $1.59 \pm 0.06$ & 102 & $\mathrm{NU}$ \\
\hline 11 & 350 & 40 & 850 & $1.5 \pm 0.06$ & $1.2 \pm 0.04$ & $1.25 \pm 0.052$ & $1.92 \pm 0.06$ & 83 & $\mathrm{NU}$ \\
\hline 12 & 350 & 50 & 850 & $1.3 \pm 0.06$ & $1.0 \pm 0.04$ & $1.30 \pm 0.061$ & $2.09 \pm 0.04$ & 76 & UR \\
\hline 13 & 350 & 63 & 850 & $1.3 \pm 0.02$ & $0.8 \pm 0.06$ & $1.63 \pm 0.077$ & $5.47 \pm 0.06$ & 74 & UR \\
\hline 14 & 350 & 80 & 850 & $1.4 \pm 0.06$ & $0.7 \pm 0.02$ & $2.00 \pm 0.052$ & $6.80 \pm 0.08$ & 73 & UR \\
\hline 15 & 350 & 100 & 850 & $1.5 \pm 0.08$ & $0.6 \pm 0.02$ & $2.50 \pm 0.063$ & $13.95 \pm 0.16$ & 70 & NU \\
\hline 16 & 400 & 40 & 1700 & $2 \pm 0.08$ & $1.6 \pm 0.02$ & $1.25 \pm 0.042$ & $3.71 \pm 0.06$ & 105 & $\mathrm{NU}$ \\
\hline 17 & 400 & 50 & 1700 & $2 \pm 0.1$ & $1.4 \pm 0.06$ & $1.43 \pm 0.066$ & $4.45 \pm 0.12$ & 102 & $\mathrm{NU}$ \\
\hline 18 & 400 & 63 & 1700 & $1.9 \pm 0.08$ & $1.1 \pm 0.06$ & $1.73 \pm 0.069$ & $6.99 \pm 0.14$ & 83 & $\mathrm{NU}$ \\
\hline 19 & 400 & 80 & 1700 & $1.8 \pm 0.08$ & $0.9 \pm 0.04$ & $2.00 \pm 0.063$ & $7.36 \pm 0.08$ & 66 & $\mathrm{NU}$ \\
\hline 20 & 400 & 100 & 1700 & $1.9 \pm 0.1$ & $0.8 \pm 0.04$ & $2.38 \pm 0.073$ & $7.74 \pm 0.06$ & 61 & $\mathrm{NU}$ \\
\hline 21 & 400 & 40 & 1275 & $1.9 \pm 0.08$ & $1.4 \pm 0.06$ & $1.36 \pm 0.060$ & $1.99 \pm 0.04$ & 106 & $\mathrm{NU}$ \\
\hline 22 & 400 & 50 & 1275 & $1.8 \pm 0.06$ & $1.2 \pm 0.04$ & $1.50 \pm 0.047$ & $3.37 \pm 0.1$ & 98 & $\mathrm{NU}$ \\
\hline 23 & 400 & 63 & 1275 & $1.8 \pm 0.08$ & $1.0 \pm 0.06$ & $1.80 \pm 0.075$ & $5.42 \pm 0.14$ & 91 & $\mathrm{NU}$ \\
\hline 24 & 400 & 80 & 1275 & $1.9 \pm 0.1$ & $0.9 \pm 0.04$ & $2.11 \pm 0.069$ & $5.75 \pm 0.2$ & 82 & $\mathrm{NU}$ \\
\hline 25 & 400 & 100 & 1275 & $2 \pm 0.12$ & $0.8 \pm 0.04$ & $2.50 \pm 0.078$ & $6.62 \pm 0.24$ & 75 & $\mathrm{NU}$ \\
\hline 26 & 400 & 40 & 850 & $1.8 \pm 008$ & $0.9 \pm 0.04$ & $2.00 \pm 0.063$ & $4.22 \pm 0.18$ & 79 & $\mathrm{NU}$ \\
\hline 27 & 400 & 50 & 850 & $1.7 \pm 0.06$ & $0.8 \pm 0.02$ & $2.13 \pm 0.043$ & $5.17 \pm 0.1$ & 77 & UR \\
\hline 28 & 400 & 63 & 850 & $1.6 \pm 0.08$ & $0.7 \pm 0.02$ & $2.29 \pm 0.058$ & $7.29 \pm 0.12$ & 69 & UR \\
\hline 29 & 400 & 80 & 850 & $1.8 \pm 0.08$ & $0.6 \pm 0.02$ & $3.00 \pm 0.056$ & $8.82 \pm 0.16$ & 60 & UR \\
\hline 30 & 400 & 100 & 850 & $1.9 \pm 0.1$ & $0.5 \pm 0.04$ & $3.80 \pm 0.096$ & $10.97 \pm 0.3$ & 39 & NU \\
\hline 31 & 450 & 40 & 1700 & $2.1 \pm 0.1$ & $1.5 \pm 0.06$ & $1.40 \pm 0.062$ & $2.88 \pm 0.12$ & 98 & $\mathrm{NU}$ \\
\hline 32 & 450 & 50 & 1700 & $2.1 \pm 0.1$ & $1.3 \pm 0.04$ & $1.62 \pm 0.057$ & $5.90 \pm 0.18$ & 87 & $\mathrm{NU}$ \\
\hline 33 & 450 & 63 & 1700 & $2 \pm 0.1$ & $1.0 \pm 0.04$ & $2.00 \pm 0.064$ & $6.69 \pm 0.2$ & 76 & NU \\
\hline 34 & 450 & 80 & 1700 & $1.9 \pm 0.1$ & $0.9 \pm 0.04$ & $2.11 \pm 0.069$ & $5.92 \pm 0.12$ & 71 & $\mathrm{NU}$ \\
\hline 35 & 450 & 100 & 1700 & $2.1 \pm 0.1$ & $0.8 \pm 0.04$ & $2.63 \pm 0.069$ & $20.87 \pm 0.4$ & 64 & $\mathrm{NU}$ \\
\hline 36 & 450 & 40 & 1275 & $2.2 \pm 0.12$ & $1.3 \pm 0.06$ & $1.69 \pm 0.071$ & $6.18 \pm 0.36$ & 84 & $\mathrm{NU}$ \\
\hline 37 & 450 & 50 & 1275 & $2.1 \pm 0.08$ & $1.1 \pm 0.04$ & $1.91 \pm 0.053$ & $7.91 \pm 0.32$ & 80 & $\mathrm{NU}$ \\
\hline 38 & 450 & 63 & 1275 & $1.9 \pm 0.06$ & $0.9 \pm 0.04$ & $2.11 \pm 0.055$ & $5.12 \pm 0.12$ & 77 & UR \\
\hline 39 & 450 & 80 & 1275 & $1.7 \pm 0.08$ & $0.7 \pm 0.02$ & $2.43 \pm 0.055$ & $3.40 \pm 0.1$ & 74 & UR \\
\hline 40 & 450 & 100 & 1275 & $2 \pm 0.08$ & $0.6 \pm 0.02$ & $3.33 \pm 0.052$ & $1.12 \pm 0.04$ & 61 & UR \\
\hline 41 & 450 & 40 & 850 & $1.9 \pm 0.1$ & $0.9 \pm 0.04$ & $2.11 \pm 0.069$ & $6.47 \pm 0.2$ & 77 & $\mathrm{NU}$ \\
\hline 42 & 450 & 50 & 850 & $2.1 \pm 0.12$ & $0.8 \pm 0.04$ & $2.63 \pm 0.076$ & $8.66 \pm 0.28$ & 60 & $\mathrm{NU}$ \\
\hline 43 & 450 & 63 & 850 & $1.8 \pm 0.08$ & $0.6 \pm 0.02$ & $3.00 \pm 0.056$ & $6.44 \pm 0.22$ & 52 & NU \\
\hline 44 & 450 & 80 & 850 & $2 \pm 0.1$ & $0.4 \pm 0.02$ & $5.00 \pm 0.071$ & $26.09 \pm 0.6$ & 42 & $\mathrm{NU}$ \\
\hline 45 & 450 & 100 & 850 & $0.6 \pm 0.06$ & $0.1 \pm 0.06$ & $6.00 \pm 0.608$ & -- & 30 & NU \\
\hline
\end{tabular}

Tab. 3. Values of the input parameters and geometry parameters for the main experiments (NU- Non-uniform; UR- Uniform \& regular)

Visual examination was used to observe the quality of all 45 deposition tracks obtained during the experiments so as to classify them in the categories of (i) wire dripping, (ii) wire stubbing, and (ii) regular deposition, as shown in Fig. 5. Accordingly, the corresponding parametric combinations were also identified leading to these deposition shapes. 


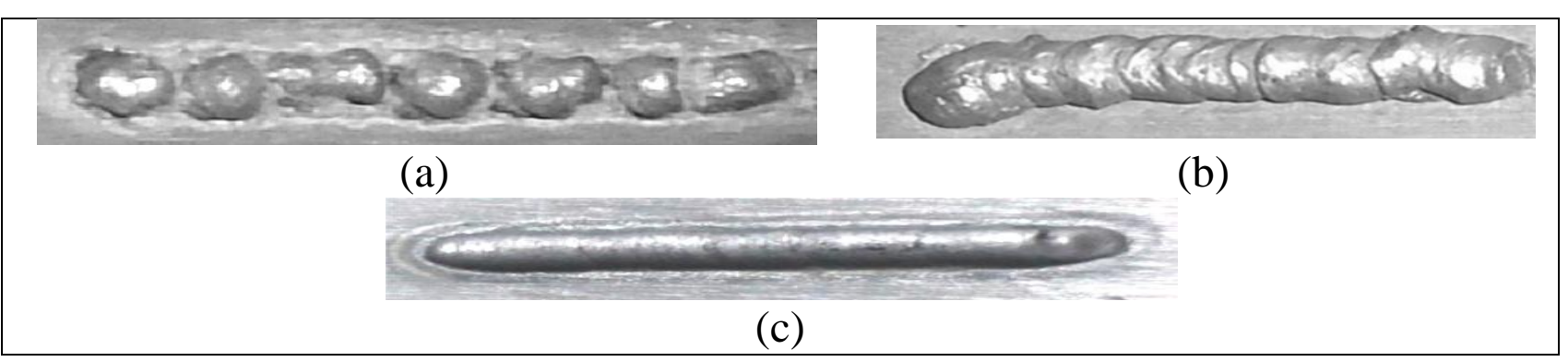

Fig. 5. Types of the single track depositions obtained, (a) wire dripping; (b) wire stubbing; and (c) regular deposition

Out of 45 combinations of the process parameters, nine combinations of wire feed rate, plasma power and travel speed of worktable were identified that produced regular deposition. These deposited tracks were cut transverse to the track length, polished and etched for standard optical microscopy. Fig. 6 presents the optical micrographs of the nine regular depositions obtained during the main experiments corresponding to the exp. no. 12, 13, 14, 27, 28, 29, 38, 39 and 40 from Tab.3. These combination of process parameters yielded regular and smooth single track geometry without defects (such as inclusion, porosity and cracks) as seen in the optical microscopy after etching with hydrofluoric acid.

The careful examination of the experimental results indicated that two parameters namely energy input per unit traverse length $\left(E_{l}\right)$ and volumetric feed rate of wire per unit traverse length $\left(V_{l}\right)$ governed the availability of plasma energy and feed material per unit travel of the worktable for a single track deposition, thus determining the material deposition rate $(G)$. Equations 1, 2 and 3 presents the mathematical representation of $E_{l}, V_{l}$ and $G$, respectively

$$
\begin{gathered}
E_{I}=\frac{60 P}{v}\left(\frac{J}{m m}\right) \\
V_{l}=\frac{A_{w} f}{v}\left(\mathrm{~mm}^{2}\right) \\
G=60 A_{w} f \rho_{w}(\mathrm{~g} / \mathrm{h})
\end{gathered}
$$

\begin{tabular}{|c|c|c|c|c|c|c|}
\hline $\begin{array}{l}\text { Exp. } \\
\text { No. }\end{array}$ & $\begin{array}{l}\text { Plasma } \\
\text { power } \\
\text { (W) }\end{array}$ & $\begin{array}{l}\text { Travel speed } \\
\text { of worktable } \\
(\mathrm{mm} / \mathrm{min} \text {. })\end{array}$ & $\begin{array}{l}\text { Wire feed } \\
\text { rate } \\
(\mathrm{mm} / \mathrm{min} .)\end{array}$ & $\begin{array}{l}\text { Energy input per unit } \\
\text { traverse length } \\
(\mathbf{J} / \mathbf{m m})\end{array}$ & $\begin{array}{lr}\text { Volumetric } & \text { feed } \\
\text { rate of wire per unit } \\
\text { traverse } \\
\left(\mathbf{m m}^{2}\right)\end{array}$ & $\begin{array}{l}\text { Material } \\
\text { deposition } \\
\text { rate }(\mathrm{g} / \mathrm{h})\end{array}$ \\
\hline 12 & 350 & 50 & 850 & 420.00 & 17 & 28.1 \\
\hline 13 & 350 & 63 & 850 & 333.33 & 13.49 & 28.1 \\
\hline 14 & 350 & 80 & 850 & 262.50 & 10.63 & 28.1 \\
\hline 27 & 400 & 50 & 850 & 480.00 & 17 & 28.1 \\
\hline 28 & 400 & 63 & 850 & 380.95 & 13.49 & 28.1 \\
\hline 29 & 400 & 80 & 850 & 300.00 & 10.63 & 28.1 \\
\hline 38 & 450 & 63 & 1275 & 428.57 & 20.24 & 42.2 \\
\hline 39 & 450 & 80 & 1275 & 337.50 & 15.94 & 42.2 \\
\hline 40 & 450 & 100 & 1275 & 270.00 & 12.75 & 42.2 \\
\hline
\end{tabular}

Here, $A_{w}$ is the cross section area $\left(\mathrm{mm}^{2}\right)$ and $\rho_{w}$ is the density of the wire $\left(/ \mathrm{mm}^{3}\right)$

Tab. 4. Experimental conditions for regular deposition 
Tab. 4 presents the experimental conditions for regular deposition. These experimental conditions can be further optimized by estimation of depsotion geometry (Jhavar et al 2014c). A comparison of various parameters as derived from Equations 1- 3 showed that the maximum material deposition rate with least plasma energy input per unit traverse length and nominal volume wire feed per unit traverse length of substrate for the combination of process parameters as described for experiment no. 40. Fig. 7 presents the process-window indicating various deposition zones, i.e., good deposition, wire dripping and wire stubbing with respect to various input energy per unit traverse length and wire feed per unit traverse length. It reveals that the minimum wire feed per unit length and energy input per unit traverse length required are $10.63 \mathrm{~mm} / \mathrm{min}$ and $262.5 \mathrm{~J} / \mathrm{mm}$ respectively for regular deposition. Whereas, for regular deposition maximum wire feed per unit traverse length and energy input per unit traverse length required are $20.24 \mathrm{~mm} / \mathrm{min}$ and $480 \mathrm{~J} / \mathrm{mm}$ respectively. The data presented here is constrained by the current setup and processing parameters. It may be noted that there was a balance of input energy per unit traverse length and high wire feed rate required for sound deposition.

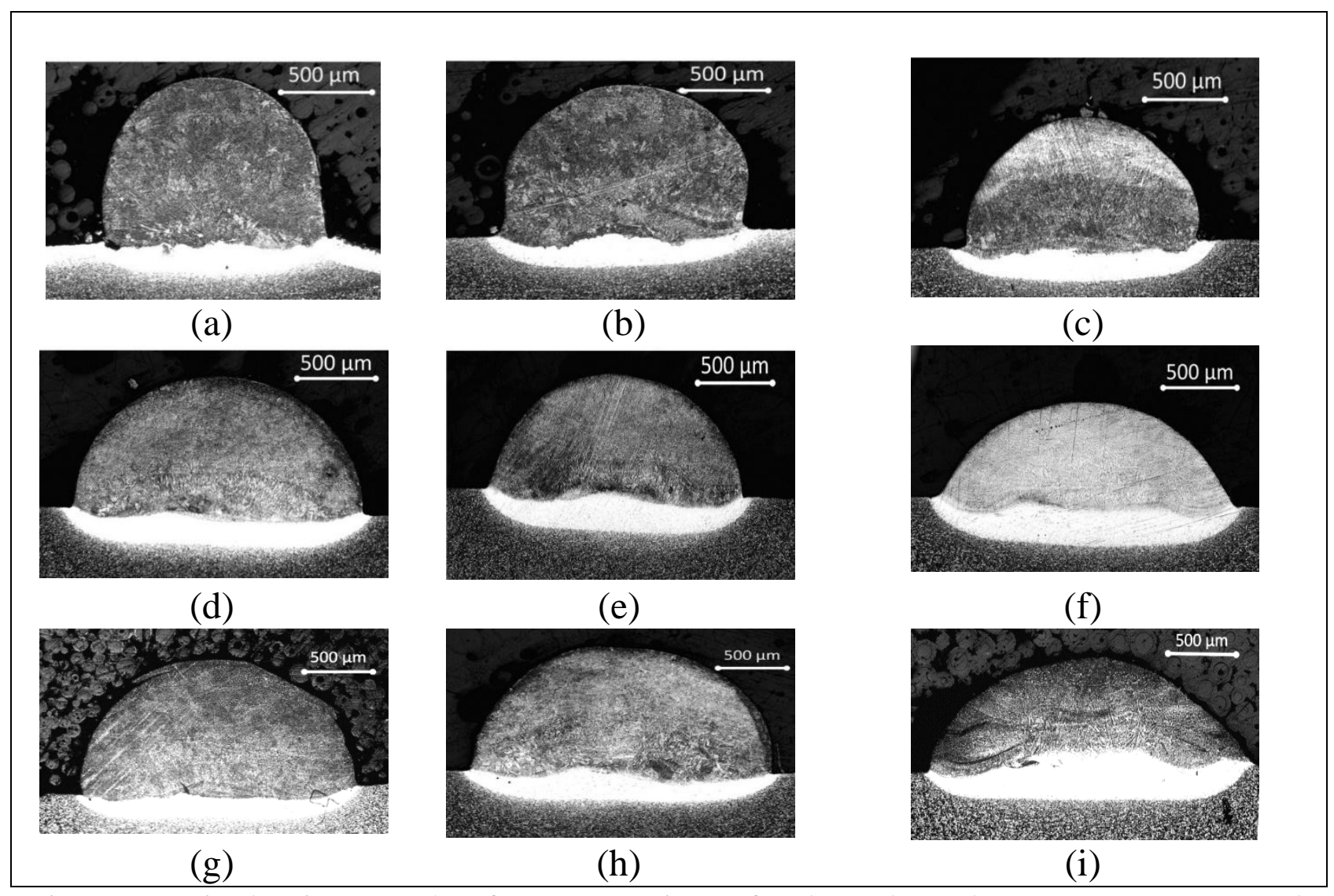

Fig. 6. Optical micrograph of cross-section of selected tracks (a) exp. no. 12; (b) exp. no. 13; (c) exp. no. 14; (d) exp. no. 27; (e) exp. no. 28; (f) exp. no. 29; (g) exp. no. 38; (h) exp. no. 39; and (i) exp. no. 40 (Jhavar et al. 2014b) 


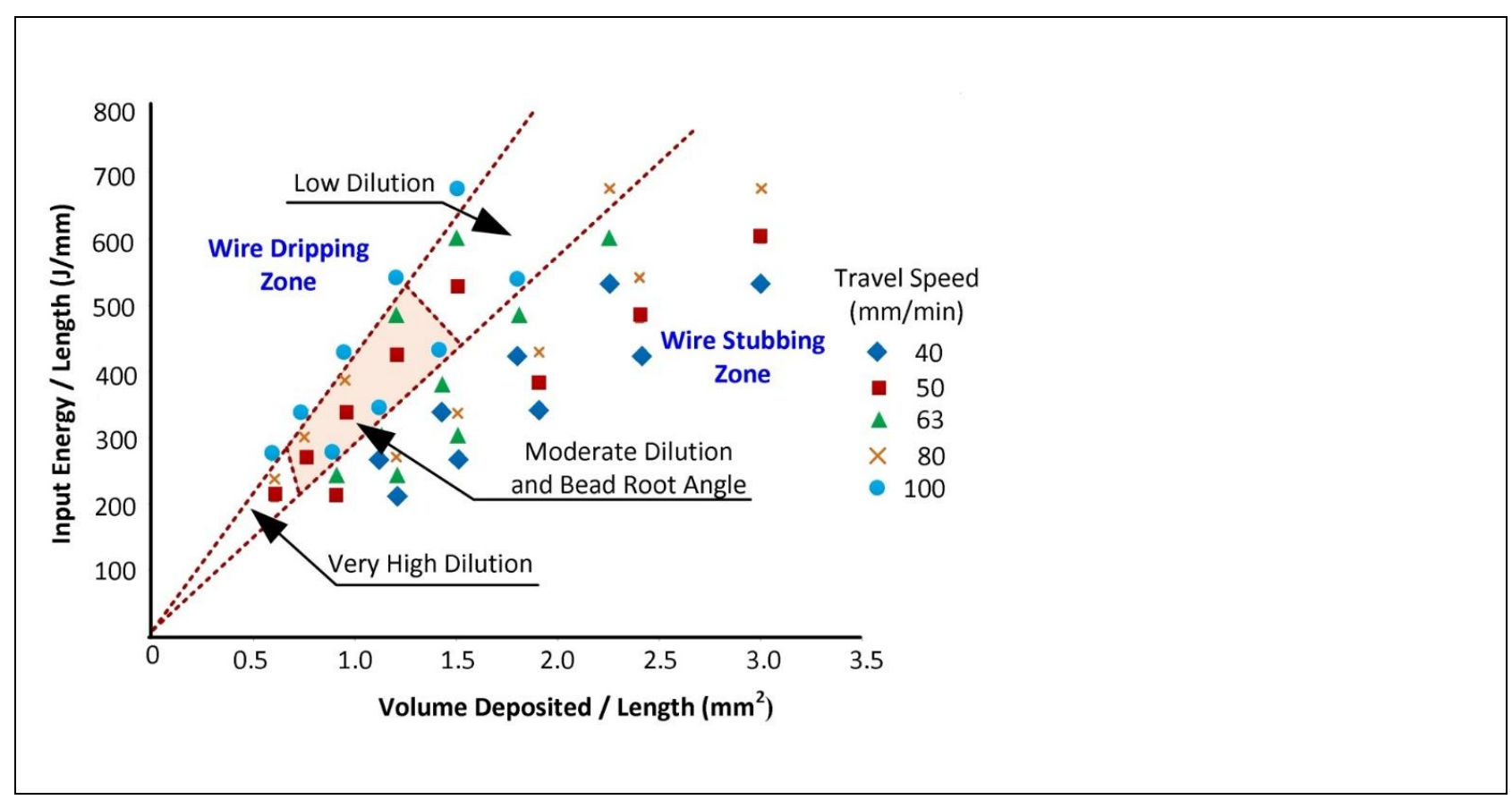

Fig. 7. Process-window indicating various deposition zones during micro-plasma wire deposition process

Out of the nine parametric combinations, the one which gave the lowest plasma energy input per unit traverse length and highest deposition rate (i.e. experiment no. 40 in Tab. 4) was selected for multi-layer deposition of a straight wall consisting of 15 layers with a deposition length of $50 \mathrm{~mm}$ for each layer. The deposition was started from the end point of the previous layer for each subsequent layer. The experiment was repeated thrice to confirm the process accuracy. The average values of deposition height measured from the substrate were $7.6 \mathrm{~mm}, 8 \mathrm{~mm}$ and $7.8 \mathrm{~mm}$ for the three fabricated multi-layer deposited straight walls. Fig. 8 shows geometry of the best quality multi-layer deposited sample. While, Fig. 9 depicts the cross-section of multi-layer deposition. It can be seen from these figures that the multi-layer deposition gave smooth but little wavy surface topography necessitating some finishing operation to achieve planer deposition surface. It also signifies the complete melting of deposition wire during deposition and good bonding between the intermediate layers. The samples were subjected to dye penetration tests and it was confirmed that the deposited samples were free from defects such as cracks, porosity and inclusions at the surface.

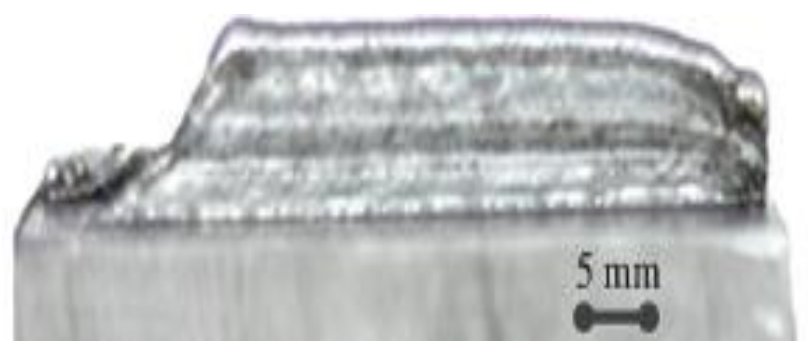

Fig. 8. Geometry of wall fabricated by multi-layer deposition 


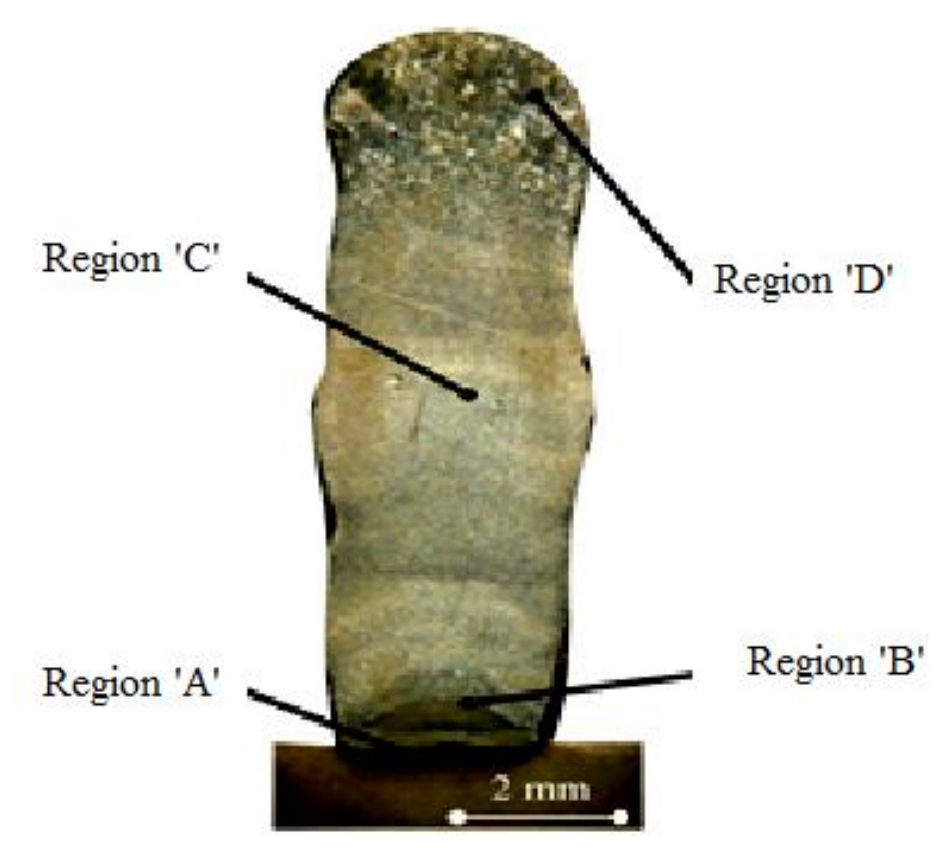

Fig. 9. Crosssection of multi-layer deposition depicting various regions for SEM evaluation

From the SEM images shown in the Fig. 10, it can be observed that the multilayer deposition had dense structure having uniform and non-dendritic grains at a particular location and was free from porosity, inclusions and cracks. Microscopy of the samples also confirmed that there was no inter-layer or trans-layer porosity in the samples. The depositions were smooth and had good bonding strength with the substrate and inter-layer depositions. The micro plasma wire deposition process was able to fabricate straight wall having total wall width (TWW) of $2.45 \mathrm{~mm}$ and effective wall width (EWW) of $2.11 \mathrm{~mm}$. The deposition efficiency was found to be in a range of $87-95 \%$ with a maximum deposition rate being $42 \mathrm{~g} / \mathrm{h}$. The microhardness measurement of the micro plasma wire deposition material across the crosssection was measured. Fig. 11 shows values of the micro-hardness along the height of deposition. A minimum hardness value of $253 \mathrm{HV}_{500 \mathrm{gf}}$ was found near to the top layer and a maximum hardness value of $616 \mathrm{HV}_{500 \mathrm{gf}}$ in the HAZ. Little variation in micro-hardness was found within a particular layer whereas; there is a significant variation across the deposited layers. It can also be observed that the high values of micro-hardness are recorded near the HAZ which is very narrow and spreads up-to few $\mathrm{mm}$. The subsequent layers towards the top witnessed a decrease in the microhardness values. This is due to the fact that the initial layers are deposited over a substrate at room temperature, which acts as a heat sink gives higher cooling rate as compared to that for the subsequent layers. The hardness in the HAZ can be minimized using a preheated substrate or post-deposition heat treatment. The deposition above few initial layers were found almost harmonized and the hardness values of these zones were found near to that of substrate. 


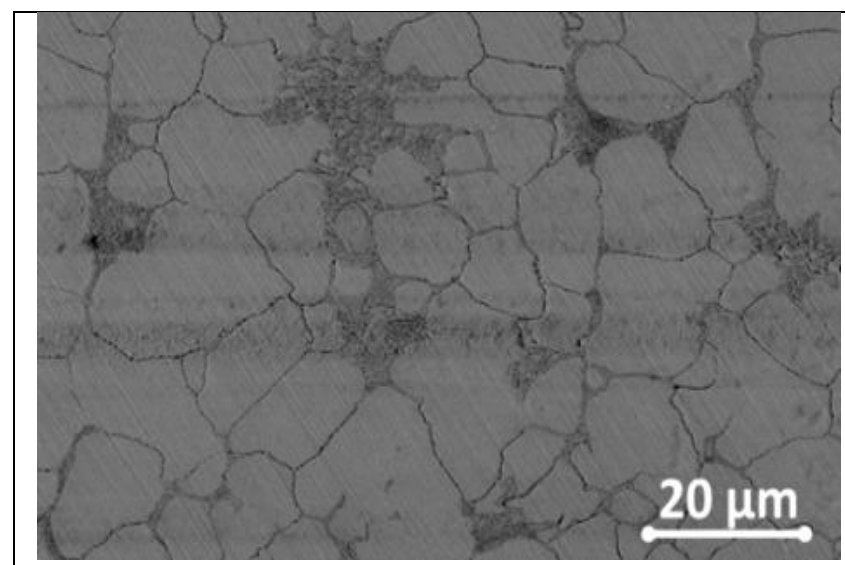

(a)

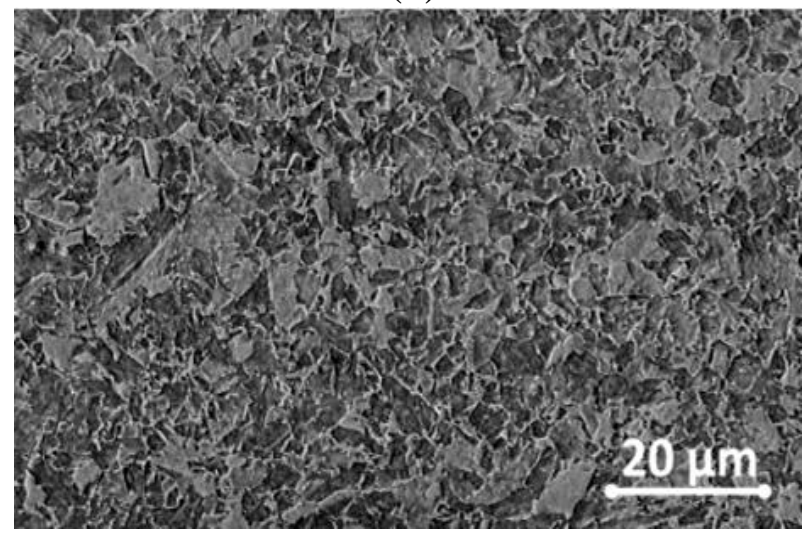

(c)

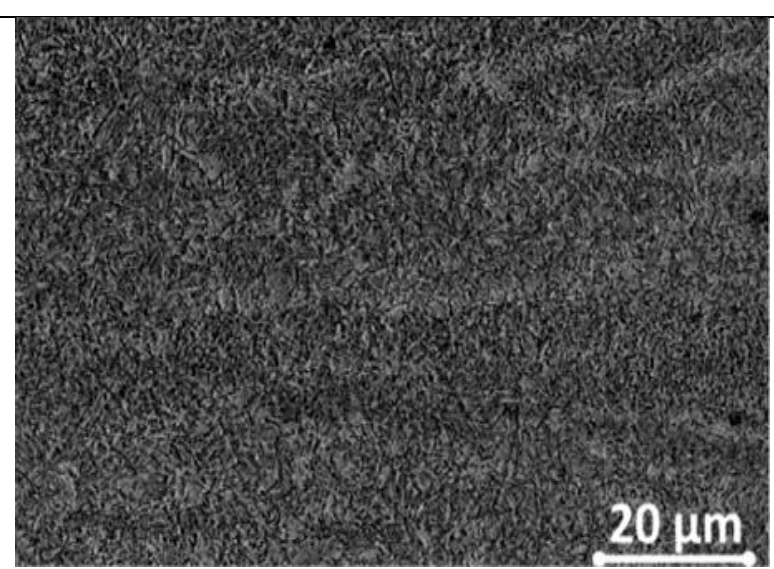

(b)

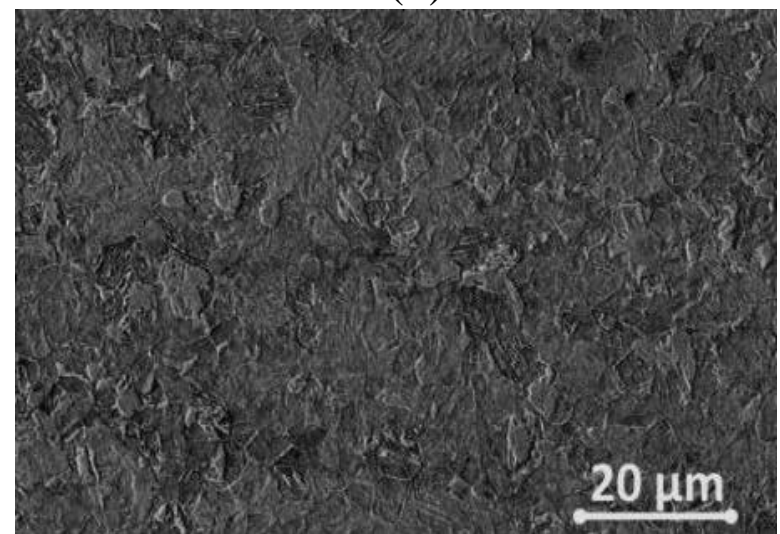

(d)

Fig. 10. SEM micrographs representing various parameters used to judge the quality characteristics of multi-layer wall deposition, (a) region ' $A$ ' in HAZ; (b) region ' $\mathrm{B}$ ' $1 \mathrm{~mm}$ above the substrate; (c) region ' $\mathrm{C}$ ' $3 \mathrm{~mm}$ above the substrate and (d) region ' $\mathrm{D}$ ' $6 \mathrm{~mm}$ above the substrate

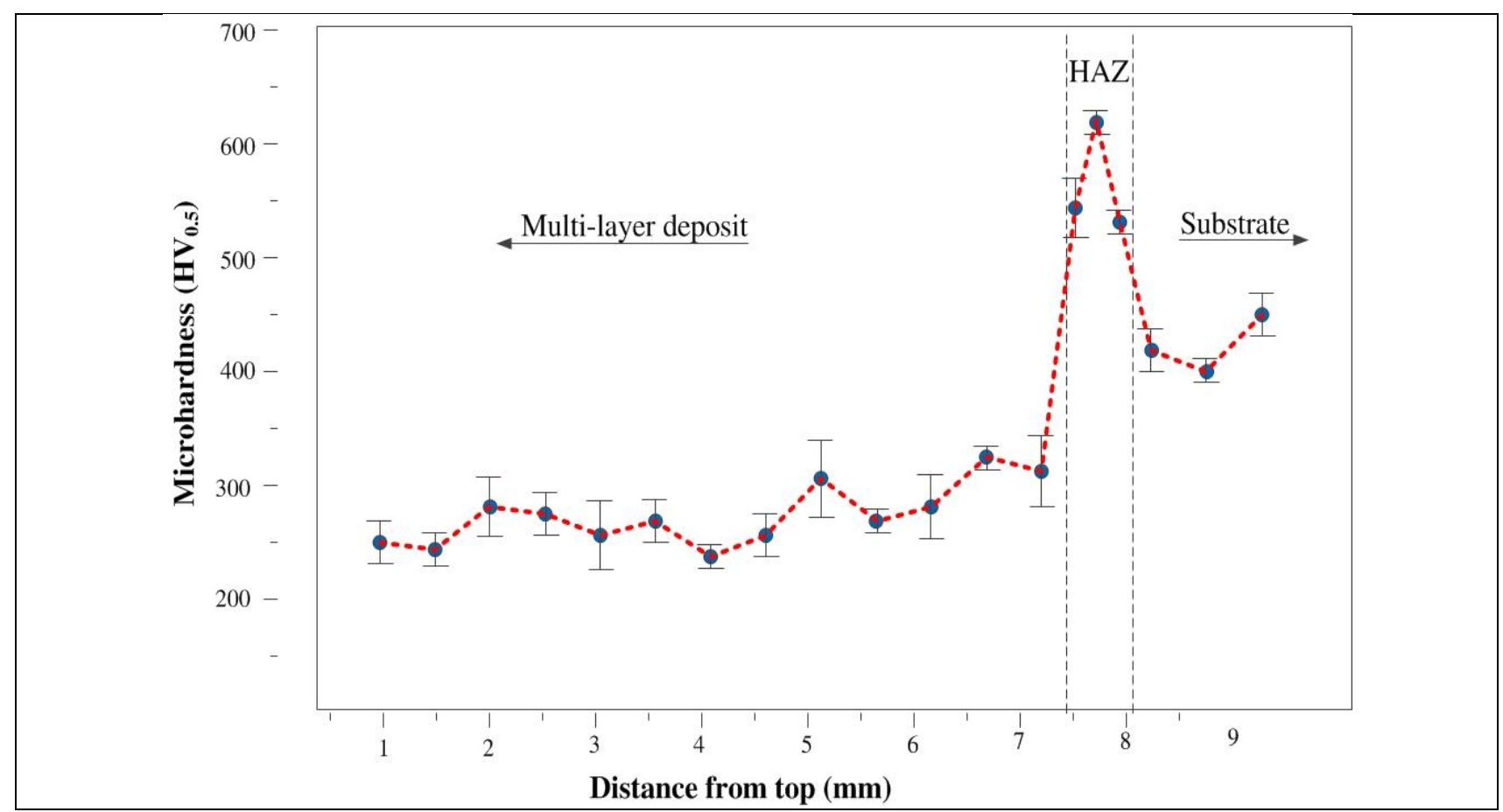

Fig. 11. Micro-hardness profile for the best quality multi-layer deposited sample (Jhavar et al., 2014b) 


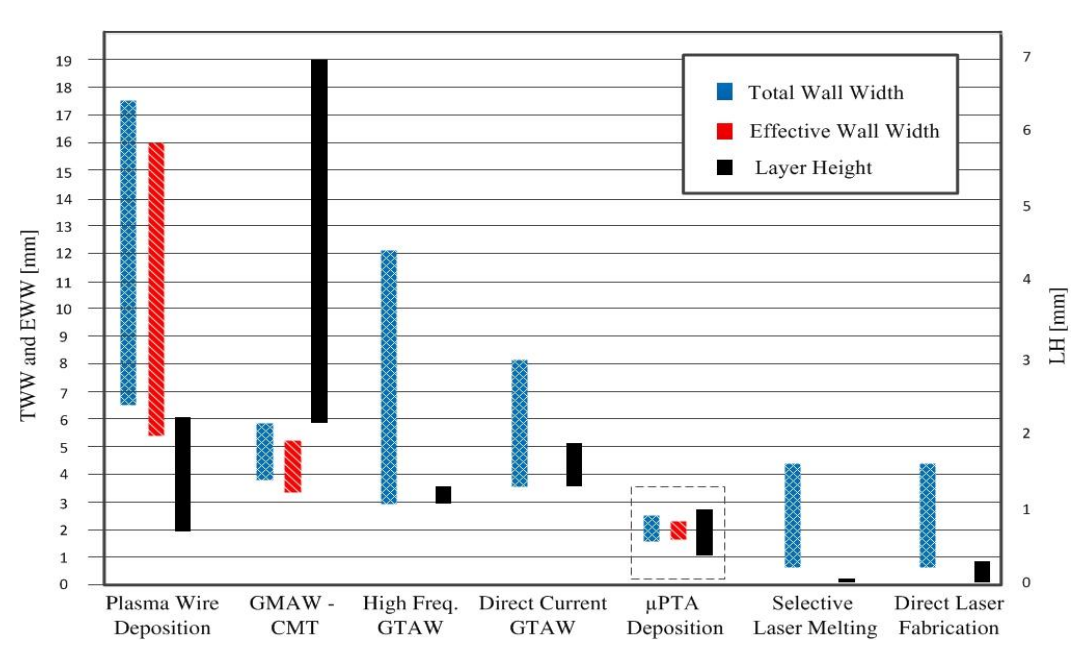

Fig. 12. Micro plasma wire deposition process compared with other LM processes (Jhavar et al. 2014 )

\section{Comparison of micro-plasma with Existing LM Processes}

Tab. 5 presents comparison of the results of present work with some of the most recent experimental studies on multi-layer wall deposition using single bead geometry in terms of the energy source used, deposition material and its form, energy consumption per unit traverse length $(\mathrm{J} / \mathrm{mm})$, consumption rate of the deposition material, power consumption per unit deposition material consumption and TWW achieved by these processes.

\begin{tabular}{|l|l|l|l|l|l|l|}
\hline $\begin{array}{l}\text { Authors } \\
\text { (year) }\end{array}$ & $\begin{array}{l}\text { Type of } \\
\text { energy } \\
\text { source }\end{array}$ & $\begin{array}{l}\text { Deposition } \\
\text { material and } \\
\text { its form }\end{array}$ & $\begin{array}{l}\text { Energy } \\
\text { consumption } \\
\text { per unit } \\
\text { traverse length } \\
\text { (J/mm) }\end{array}$ & $\begin{array}{l}\text { Consumption } \\
\text { rate of the } \\
\text { deposition } \\
\text { material }\end{array}$ & $\begin{array}{l}\text { Power } \\
\text { consumption } \\
\text { per unit } \\
\text { deposition } \\
\text { material } \\
\text { consumption }\end{array}$ & TWW \\
\hline $\begin{array}{l}\text { Bi \& Gasser } \\
(2011)\end{array}$ & $\begin{array}{l}\text { Nd:YAG } \\
\text { laser }\end{array}$ & $\begin{array}{l}\text { Powder of Ni- } \\
\text { based super } \\
\text { alloy }\end{array}$ & $36 \mathrm{~J} / \mathrm{mm}$ & $1.5 \mathrm{~g} / \mathrm{min}$. & $12,000 \mathrm{~J} / \mathrm{g}$ & $1.3 \mathrm{~mm}$ \\
\hline $\begin{array}{l}\text { Gharbi et al. } \\
(2013)\end{array}$ & $\begin{array}{l}\text { Yb:YAG } \\
\text { laser }\end{array}$ & $\begin{array}{l}\text { Powder of } \\
\text { Ti-6Al-4V }\end{array}$ & $48-75 \mathrm{~J} / \mathrm{mm}$ & $1 \mathrm{~g} / \mathrm{min}$. & $\begin{array}{l}19,200-30,000 \\
\mathrm{~J} / \mathrm{g}\end{array}$ & $\begin{array}{l}1.9-2.1 \\
\mathrm{~mm}\end{array}$ \\
\hline $\begin{array}{l}\text { Ravi et al. } \\
(2013)\end{array}$ & Disc laser & $\begin{array}{l}\text { Powder of } \\
\text { SC420 }\end{array}$ & $7.0-67.5 \mathrm{~J} / \mathrm{mm}$ & $2.6-12 \mathrm{~g} / \mathrm{min}$. & $\begin{array}{l}2,304-9,000 \\
\mathrm{~J} / \mathrm{g}\end{array}$ & $\begin{array}{l}0.5-4.0 \\
\mathrm{~mm}\end{array}$ \\
\hline $\begin{array}{l}\text { Zhao et al. } \\
(2012)\end{array}$ & GMAW & $\begin{array}{l}1.2 \mathrm{~mm} \\
\text { diameter wire } \\
\text { of H08Mn2Si }\end{array}$ & $1490 \mathrm{~J} / \mathrm{mm}$ & $2,880 \mathrm{~mm} / \mathrm{min}$. & $50.4 \mathrm{~J} / \mathrm{mm}$ & $\mathrm{N} . \mathrm{A}$. \\
\hline Present work & $\begin{array}{l}\text { Micro- } \\
\text { plasma }\end{array}$ & $\begin{array}{l}0.3 \mathrm{~mm} \\
\text { diameter wire } \\
\text { of AISI P-20 } \\
\text { steel }\end{array}$ & $270 \mathrm{~J} / \mathrm{mm}$ & $1,275 \mathrm{~mm} / \mathrm{min}$. & $21.1 \mathrm{~J} / \mathrm{mm}$ & $\begin{array}{l}2.45 \\
\mathrm{~mm}\end{array}$ \\
\hline
\end{tabular}

Tab. 5. Comparison of the outcome of the present work with some of the most recent experimental studies on single bead multi-layer wall deposition (Jhavar et al. 2014b)

It can be observed from this comparison that though the laser based deposition processes require very less energy input per unit traverse length but their power consumption for per unit of deposition material is very high. Moreover, they have 
poor energy conversion efficiency. While, conventional arc based deposition processes require very high energy per unit traverse length and use high feed rate of the deposition material but consume less power per unit deposition material consumption. They also focus higher amount of heat over larger area therefore it is difficult to use these processes for meso-scale deposition. It is evident from Table 5 that micro plasma wire deposition process is very economical and energy efficient because it requires much less power consumption per unit deposition material consumption as compared to the laser and arc based processes. Fig. 12 compares the performance of the micro plasma wire deposition process with the other competitive processes as reported by Martina et al. (2012) in terms of terms of TWW, EWW and layer height (LH). It reveals that though plasma wire deposition (PWD) can achieve smaller size deposition than the gas metal arc welding (GMAW) based processes but, it cannot achieve very small size deposition which can be achieved by the laser based processes. It is also evident from the comparison of Fig. 12 that micro plasma wire deposition process can bridge this gap and can fabricate the meso-scale components. Use of finer wire can further reduce the deposition size enabling micro plasma wire deposition process to fabricate the miniaturized parts and offer the capabilities of laser based processes at much lower cost and power consumption per unit deposition material consumption.

\section{Conclusions}

The work presented in this thesis illustrates the potential of micro plasma wire deposition process for layer manufacturing. Following conclusions can be drawn from the present research:

1. Micro plasma wire deposition involved low heat input as it is capable of depositing small volumes per unit length during the process.

2. For regular deposition maximum wire feed per unit traverse length and energy input per unit traverse length required are $20.24 \mathrm{~mm} / \mathrm{min}$ and $480 \mathrm{~J} / \mathrm{mm}$ respectively.

3 . The plasma energy per unit of traverse length and volumetric wire feed rate of wire per unit traverse length were found to have threshold values of $262 \mathrm{~J} / \mathrm{mm}$ and 10.6 $\mathrm{mm}^{3} / \mathrm{mm}$ respectively for the regular and continuous deposition yielding a deposition rate of $28.1 \mathrm{~g} / \mathrm{h}$.

4. The values of aspect ratio ranges between 1.3 to 4 , percentage dilution ranging between 2 to 8 , and track root angle ranging between $60^{\circ}$ to $77^{\circ}$ was observed for smooth and regular deposition.

5. Multi-layer deposition consisted of fully dense structure of good surface quality.

6. The deposition above few initial layers was found to be homogeneous and the hardness values of these zones were found near to that of the substrate.

7. Micro-plasma wire deposition process was able to fabricate straight wall consisting of 15 layers having TWW of $2.45 \mathrm{~mm}$ and a EWW of $2.11 \mathrm{~mm}$ with a deposition efficiency of $87 \%$. It could achieve maximum deposition rate of $42 \mathrm{~g} / \mathrm{h}$.

8. Micro plasma wire deposition process confirmed to be cost-effective, material efficient, energy efficient and environmental friendly process for multi-layer 
deposition and has the potential to become an alternative LM process for metallic materials.

\section{Scope for the future work}

The present work was the first attempt to establish micro plasma wire deposition process as an alternative to the existing LM processes therefore there is a lot of scope for future research in this area. Scope for future work may include the following:

1. Present study was conducted using conventional milling machine as manipulator system. The study can be extended to use of automated manipulators such as CNC machine or robotic arc. The deposition is expected to thereby improve in terms of deposition quality with more precision and less surface waviness.

2. Present study was limited to use of AISI P20 wires of $300 \mu \mathrm{m}$. However, several other materials can also be used to extend the application of micro plasma wire deposition process in areas of avionics and aerospace, nuclear, biomedical and others. Use of small sized wire is also expected to give better deposition for miniaturized components.

3. Use of three dimensional heat transfer analysis using computer aided design tools (CAE) can be helpful to study the effect of plasma energy on heat affected zone and their effects can be minimized.

4. The process can be modified with the use of adaptive control to increase its capability to perfectly challenge high energy beam LM processes.

5 . The process can be extended for manufacturing of functionally graded material (FGM) and metal matrix composites (MMC).

6. Use of powder based material is also an unexplored area of micro plasma wire deposition process. Its relative advantages and limitations over wire based deposition can also be studied.

\section{References}

Abioye, T.E.; Folkes, J. \& Clare, A.T. (2013). A parametric study of Inconel 625 wire laser deposition. Journal of Materials Processing Technology, 212, 203-210 Akula, S. \& Karunakaran, K.P. (2006). Hybrid adaptive layer manufacturing: An Intelligent art of direct metal rapid tooling process. Robotics and ComputerIntegrated Manufacturing, 22, 113-123

Almeida, P.M.S. \& Williams, S. (2010). Innovative process model of Ti-6Al-4V additive layer manufacturing using cold metal transfer (CMT). Proceedings of the 21st Annual International Solid Freeform Fabrication Symposium, 25-36

Baufeld, B.; Brandl, E. \& Biest, O.V.D. (2011). Wire based additive layer manufacturing: Comparison of microstructure and mechanical properties of $\mathrm{Ti}-6 \mathrm{Al}-$ $4 \mathrm{~V}$ components fabricated by laser-beam deposition and shaped metal deposition. Journal of Materials Processing Technology, 211, 1146-1158

Bi, G. \& Gasser, A. (2011). Restoration of nickel-base turbine blade knife-edges with controlled laser aided additive manufacturing. Physics Procedia, 12, 402-209

Campbell, R.I. 2007. How designers can exploit rapid manufacturing's capabilities to add value to products. In Drstvensek, I and Katalanic, B (ed) The 1st DAAAM 
Jhavar, S. \& Jain, N.: Development of Micro-Plasma Wire Deposition Process for L...

International Specialized Conference on Additive Technologies, Proceedings of the 1st DAAAM International Specialized Conference on Additive, Celje, Slovenia, pp.3-4, ISBN: 3901509615

Gharbi, M.; Peyre, P., Gorny, C., Carin, M., Morville, S., Masson, P.L., Carron, D. \& Fabbro, R. (2013). Influence of various process conditions on surface finishes induced by the direct metal deposition laser technique on a $\mathrm{Ti}-6 \mathrm{Al}-4 \mathrm{~V}$ alloy. Journal of Materials Processing Technology, 213, 791- 800

Hopkinson, N. \& Dickens, P., 2006. Emerging rapid manufacturing processes. In: Hopkinson, N., Hague, R., Dickens, P., (Eds.), An industrial revolution for the digital edge, John Wiley \& Sons Ltd., England, pp. 55-80

Horii, T.; Kirihara, S. \& Miyamoto, Y. (2009). Freeform fabrication of superalloy objects by 3D micro welding. Materials and Design, 30, 1093-1097

Jandric, Z.; Labudovic, M. \& Kovacevic, R. (2004). Effect of heat sink on microstructure of three-dimensional parts built by welding-based deposition. International Journal of Machine Tools \& Manufacture, 44, 785-796

Jhavar, S.; Jain, N.K. \& Paul, C.P. (2014b). Development of micro-plasma transferred arc ( $\mu$-PTA) wire deposition process for additive layer manufacturing applications. Journal of Materials Processing Technology, 214, 5, 1102-1110

Jhavar, S.; Jain, N.K. \& Paul, C.P. (2014c). Enhancement of deposition quality in micro-plasma transferred arc deposition process. Materials and Manufacturing Processes, 29, 8, 1017-1023

Jhavar, S.; Paul, C.P. \& Jain, N.K. (2013). Causes of Failure and Repairing Options for Dies and Molds: A Review. Engineering Failure Analysis, 34, 519-535

Jhavar, S.; Paul, C.P. \& Jain, N.K. (2014a). Experimental investigation on geometrical aspects of micro-plasma deposited tool steel for repair applications. International of Journal of Modern Physics: Conference Series 32, 1460347

Levy, G.N.; Schindel, R. \& Kruth, J.P. (2003). Rapid manufacturing and rapid tooling with layer manufacturing (LM) technologies: state of the art and future perspectives. CIRP Annals - Manufacturing Technology, 52, 2, 589-609

Martina, F.; Mehnen, J., Williams, S.W., Colegrove, P. \& Wang, F. (2012). Investigation of the benefits of plasma deposition for the additive layer manufacture of Ti-6Al-4V. Journal of Materials Processing Technology, 212, 1377-1386

Ravi, G.A.; Hao, X.J., Wain, N., Wu, X. \& Attallah, M.M. (2013), Direct laser fabrication of three dimensional components using SC420 stainless steel. Materials and Design, 47, 731-736.

Suryakumar, S.; Karunakaran, K.P., Bernard, A., Chandrasekhar, U., Raghavender N. \& Sharma, D. (2011). Weld bead modeling and process optimization in hybrid layered manufacturing. Computer Aided Design, 43, 331-344

Wang, H.; Jiang, W., Valant, M. \& Kovacevic, R. (2003). Micro plasma powder deposition as a new solid freeform fabrication process. Proceedings of the Institution of Mechanical Engineers, 217, 1641-1650

Wohlers, T. T. 2006. Rapid Prototyping \& Manufacturing State of the Industry, Wohlers Report 2006. Fort Collins, CO, USA

Wong, K.V. \& Hernandez, A., 2012. A review of additive manufacturing. ISRN Mechanical Engineering, article ID 208760

Zhao, H.; Zhang, G., Yin, Z. \& Wu, L. (2012). Three-dimensional finite element analysis of thermal stress in single-pass multi-layer weld-based rapid prototyping. Journal of Materials Processing Technology, 212, 276-285 